\title{
Late reoperation after proximal repair of supravalvular stenosis for diffuse form of Williams-Beuren syndrome
}

\author{
Shintaro Katahira, MD, PhD, Yukiharu Sugimura, MD, Artur Lichtenberg, MD, $\mathrm{PhD}$, and \\ Payam Akhyari, MD, PhD, Düsseldorf, Germany
}



Video clip is available online.

Williams-Beuren syndrome is associated with various pathologies caused by a genetic mutation affecting elastin genes on chromosome 7. Elastin is a protein that plays an important role in cardiovascular tissues and is often associated with supravalvular aortic stenosis (SVAS). In this case, a mid-aged patient with previous valvuloplasty and aortic root enlargement using the Doty technique in the childhood presented with severe combined aortic valve disease and panaortic stenosis beginning at the proximal ascending aorta and further complicated by a proximal stenosis of the brachiocephalic artery. Mechanical aortic valve replacement combined with patch enlargement of the aorta from the root to the mid-portion of the aortic arch was performed.

\section{CASE REPORT}

A 41-year-old man with Williams-Beuren syndrome prediagnosed in early childhood presented with dyspnea New York Heart Association class III due to severe aortic valve regurgitation and stenosis with a progressive decline in the past 6 months. At the age of 6 years, he had undergone surgical correction for severe SVAS using the Doty method. After the operation, he regularly visited an outpatient care program. Due to unclear syncope, emergency admission and cardiac diagnostic workup was initiated, revealing an aortic valve maximum flow velocity of $4.2 \mathrm{~m} / \mathrm{s}$, average

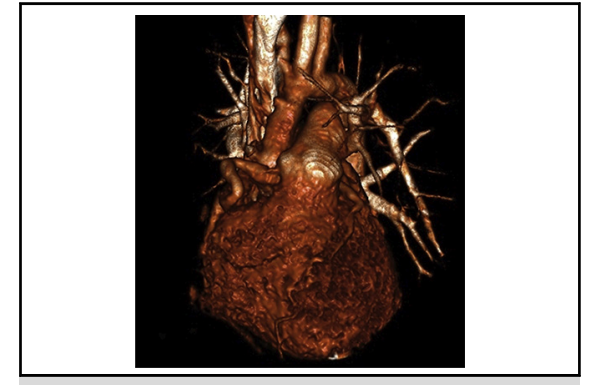

Diffuse type supravalvular aortic stenosis in Williams-Beuren Syndrome.

\section{CENTRAL MESSAGE \\ A reoperation with aortic patch plasty from root to arch is pre- sented for diffuse type of supra- valvular aortic stenosis in the adult.}

See Commentaries on pages $\mathbf{8 2}, 83$, and 85 .

pressure difference of $45.8 \mathrm{~mm} \mathrm{Hg}$, and aortic valve orifice area of $0.76 \mathrm{~cm}^{2}$. Contrast-enhanced computed tomography revealed diffuse SVAS extending from the proximal ascending aorta to the aortic arch with a maximum diameter of $14 \mathrm{~mm}$ on the level of the ascending aorta, with additional severe stenosis of the brachiocephalic artery (Figure 1) resulting in a blood pressure difference of $30 \mathrm{~mm} \mathrm{Hg}$ between the left and right upper arm. Reoperation using median re-sternotomy and extracorporeal circulation via right femoral vessels was performed with a target body core temperature of $25^{\circ} \mathrm{C}$ using cold blood cardioplegia. Severely calcified aortic valve cusps were resected. Aortotomy incision was extended into the previously implanted Dacron patch in the noncoronary sinus and slightly beyond the aortic annulus, allowing for a second root enlargement using a woven polyester graft to accommodate a mechanical prosthesis (22-mm ATS; Medtronic, Minneapolis, Minn) in the epiannular position. At circulatory arrest, the distal ascending aorta including the stenosed origin of the brachiocephalic trunk was resected with the incision to the minor curvature of the aortic arch continuing to the level of the left carotid artery. A 24-mm vascular prosthesis (FlowWave BIOSEAL; JOTEC Co, 


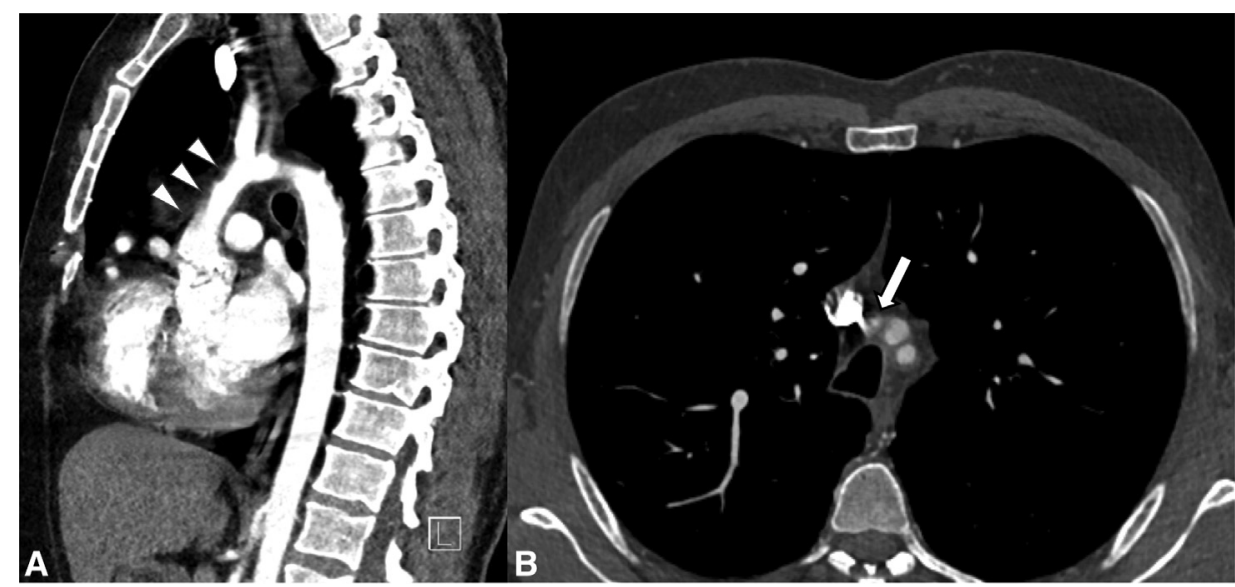

FIGURE 1. Preoperative computed tomography. A, Sagittal view demonstrates a diffuse narrowing of the entire aorta beginning at the level of sinotubular junction and ascending segment (white triangles) and extending to the abdominal aorta. B, Coronal view shows stenosis of the origin of the brachiocephalic artery (white arrow).

Ltd, Hechingen, Germany) was tailored to provide a tongue-shaped distal portion and the distal suture line resulting in enlargement of the proximal hemi-arch was performed under selective antegrade cerebral perfusion (Video 1). Extracorporeal circulation was reinitiated after de-airing and proximal anastomosis was then performed to the enlarged aortic root. The postoperative course was uneventful, and the patient was discharged 10 days postoperatively. Postoperative enhanced computed tomography showed an appropriate diameter of the ascending aorta and aortic arch. Left and right upper limbs demonstrated equal blood pressures (Figure 2). The patient has given written informed consent for scientific use and publication of his data.

\section{DISCUSSION}

Williams-Beuren syndrome is a congenital anomaly characterized by a fairy-like face, intellectual disability, and short stature along with cardiovascular abnormalities such as SVAS and peripheral pulmonary artery stenosis. ${ }^{1}$ The absence of elastin genes has been reported to be particularly involved in the development of SVAS. ${ }^{2}$ Some reports have suggested that SVAS complicated with Williams-Beuren syndrome may regress without surgical treatment. ${ }^{3}$ However, in the present case, the patient had undergone surgical correction in infancy, actually presenting with severe combined aortic valve disease.
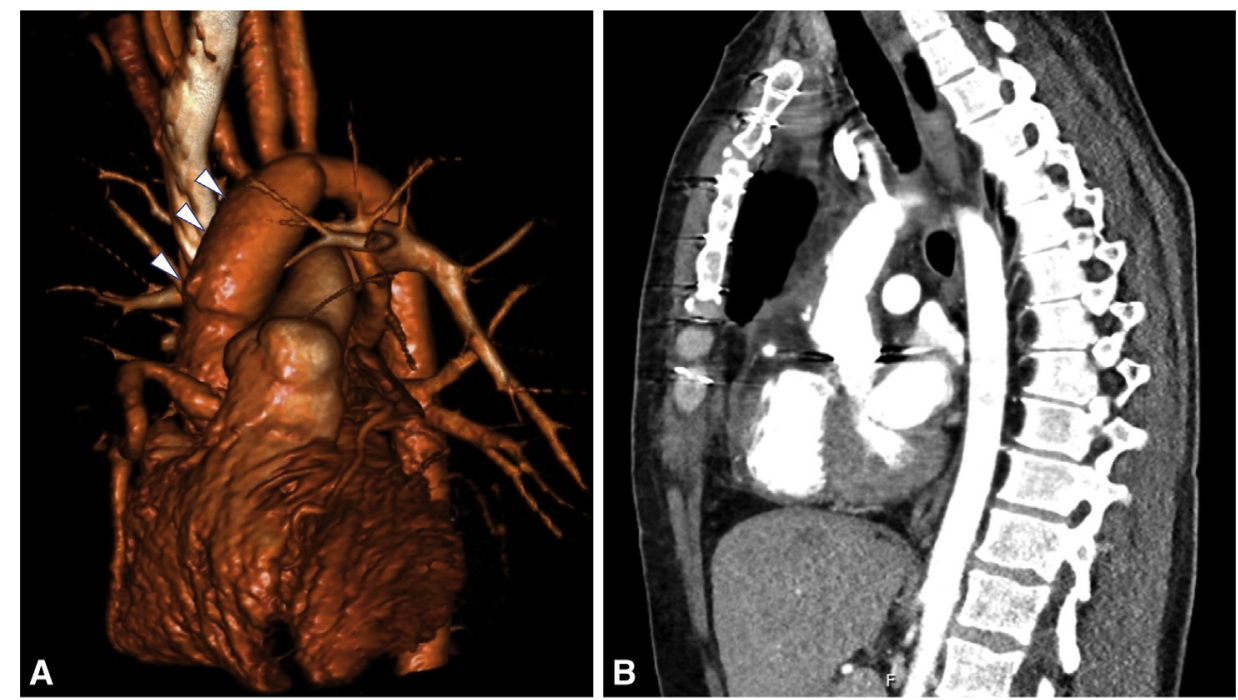

FIGURE 2. Postoperative imaging. A, Three-dimensional reconstruction demonstrates augmented aortic diameter up (white triangles) to the mid-portion of the aortic arch after patch plasty. B, Sagittal view shows the ascending aorta is enlarged to $25 \mathrm{~mm}$ and the stenosis of the brachiocephalic artery has been relieved. 


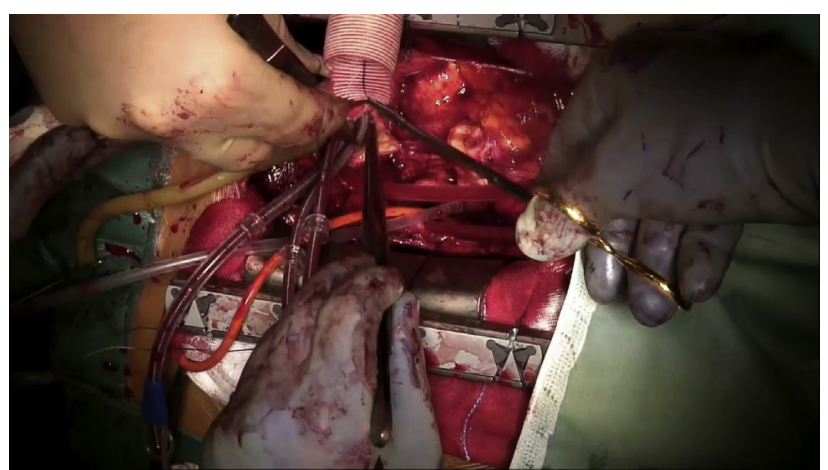

VIDEO 1. Intraoperative findings. Proximal aortic arch and brachiocephalic artery patch plasty. Video available at: https://www.jtcvs.org/ article/S2666-2507(20)30078-X/fulltext.

Although artificial vascular prosthesis replacement and patch plasty have been reported as effective treatments for diffuse SVAS, no standard surgical procedure has been defined because only few cases of the diffuse form of SVAS have been reported so far-as compared with reports on localized SVAS. ${ }^{4,5}$ Aortic root and total arch replacement may be considered as one of the radical surgical approaches in adulthood. Because of the need to insert a larger valve, we performed an aortic valve replacement with aortic annular enlargement rather than a Bentall operation. Although a further progression of the diffuse aortic stenosis is unlikely, a complete correction would theoretically need repair or replacement of the entire aorta. Thus, we opted for aortic valve replacement and enlargement of the proximal thoracic aorta to prevent the development of left ventricular dysfunction and heart failure due to valvulopathy and small aortic diameter prior to the supraaortric branches. In addition, the preoperative pressure gap was reduced.

This technique was able to release not only the proximal aortic arch stenosis but also the brachiocephalic artery stenosis, which was judged as useful in the setting of reoperation on a patient with Williams-Beuren-syndrome.

\section{References}

1. Williams JCP, Barratt-Boyes BG, Lowe JB. Supravalvular aortic stenosis. Circulation. 1961;24:1311-8.

2. Vaideeswar P, Shankar V, Deshpande JR, Sivaraman A, Jain N. Pathology of the diffuse variant of supravalvar aortic stenosis. Cardiovasc Pathol. 2001;10:33-7.

3. Hickey EJ, Jung G, Williams WG, Manlhiot C, Van Arsdell GS, Caldarone CA, et al. Congenital supravalvular aortic stenosis: defining surgical and nonsurgica outcomes. Ann Thorac Surg. 2008;86:1919-27.

4. Borghetti V, D'Addario G, Bravi I, Pardinia A. Extended replacement of a calcified ascending aorta in adulthood sporadic, diffuse type, supravalvular aortic stenosis. Interact Cardiovasc Thorac Surg. 2011;13:234-6.

5. Brown JW, Ruzmetov M, Vijay P, Turrentine MW. Surgical repair of congenital supravalvular aortic stenosis in children. Eur J Cardiothorac Surg. 2002;21:50-6. 